Journal of Accident and Emergency Medicine 1994 11, 158-161

\title{
An audit of dermatology in a paediatric accident and emergency department
}

\author{
O.M.DOLAN, ${ }^{1}$ E.A. BINGHAM, ${ }^{1}$ J.F.T.GLASGOW, ${ }^{2}$ D. BURROWS, ${ }^{1}$ \& \\ J.R. CORBETT'1 \\ ${ }^{1}$ Department of Dermatology, Royal Belfast Hospital for Sick Children, and ${ }^{2}$ Department of Child Health, \\ The Queen's University of Belfast, Northern Ireland
}

\section{SUMMARY}

Two studies were undertaken of patients with dermatological disorders who attended the Accident and Emergency (A\&E) Department of the Royal Belfast Hospital for Sick Children during 1990-1991. The aims were to review diagnostic accuracy and assess the benefits of an open-access consultant dermatology clinic.

A retrospective survey of 14340 new attendances at the A\&E department over a 7-month period found that 540 of these $(4 \%)$ had a primary dermatological disorder. In $26 \%$ no diagnosis had been made although only $10 \%$ were referred for a specialist opinion. A 2-month prospective study of patients who attended the department and were referred to a consultant dermatology open-access clinic revealed overall diagnostic accuracy of $66 \%( \pm 2$ SEM). Individual rates of diagnostic concordance between junior doctor and consultant were 59\% for skin infections and $77 \%$ for papulosquamous disorders. The open-access clinic allowed prompt referral for correct diagnosis and initiation of appropriate management.

Key words: audit, dermatology, paediatric A\&E

\section{INTRODUCTION}

It is thought three million children attend $A \& E$ departments annually in the United Kingdom, ${ }^{1}$ which is two to three times as many as attend out-patient clinics. A recent survey of one year's new attendances at this centre found that more than $60 \%$ of

Correspondence: O.M. Dolan, Department of Dermatology, Royal Victoria Hospital, Grosvenor Road, Belfast BT12 6BJ, Northern Ireland, UK $7 \%$ had a primary dermatological disorder (DD). ${ }^{2}$ However, most of the junior doctors dealing with these patients have not had supervized training or experience in dermatology.

The objective of this study was therefore to survey patients who attended a paediatric A\&E department with a DD, in order to audit diagnostic accuracy and determine the benefits of an open-access consultant dermatology clinic with the aim of improving the clinical service.

\section{METHODS}

These studies took place between September 1990 and March 1991 at the A\&E department of a children's hospital which is situated in a socially deprived inner-city area with high rates of unemployment, poor educational achievement and single parent families. From 6 August 1990 to 5 August 1991 there were 24648 new attendances by children of less than 13 years of age. The department, which is the only paediatric A\&E unit in Northern Ireland, is staffed by a part-time consultant paediatrician (0.5 WTE) and three full-time and one part-time junior medical staff. Two studies were carried out.

We reviewed retrospectively 14340 consecutive new attendances over a 7-month period. Patients with $\mathrm{DD}$ were identified, diagnoses by junior doctors reviewed and initial referral patterns determined.

A prospective study was designed to validate the diagnoses made by junior medical staff and to assess the benefits of an open-access dermatology clinic. Over a 2-month period, staff were asked to refer all patients thought to have a DD to the next consultant clinic, stating their preliminary diagnosis in the letter of referral. Open-access clinics were held daily and most patients were seen on the same or the following day.

\section{RESULTS}


An audit of dermatology

\begin{tabular}{|c|c|c|c|}
\hline & \multirow{2}{*}{$\begin{array}{c}\text { Retrospective study } \\
\text { Number (\%) }\end{array}$} & \multicolumn{2}{|c|}{ Prospective study } \\
\hline & & $\begin{array}{l}\text { Junior doctor } \\
\text { Number (\%) }\end{array}$ & $\begin{array}{c}\text { Consultant } \\
\text { Number (\%) }\end{array}$ \\
\hline Infections & $185(34)$ & $22(26)$ & $34(41)$ \\
\hline Papulosquamous & $82(15)$ & $28(34)$ & $31(38)$ \\
\hline $\begin{array}{l}\text { Urticaria and } \\
\text { toxic erythema }\end{array}$ & $57(11)$ & $8(10)$ & $11(13)$ \\
\hline Miscellaneous & $75(14)$ & $10(12)$ & $7(8)$ \\
\hline No diagnosis & $141(26)$ & $15(18)$ & $0(0)$ \\
\hline Total & $540(100)$ & $83(100)$ & $83(100)$ \\
\hline
\end{tabular}

Table 1. Results of both the retrospective survey by dermatological category and a comparison of junior doctor and consultant diagnoses in the prospective study the general practitioner (GP); the rest were parent referrals. The diagnoses, which were made largely by the junior staff, are shown in Table 1; acute or chronic infections were the largest group (185), $15 \%(82)$ were thought to have a papulosquamous disorder (atopic eczema, seborrhoeic eczema, napkin dermatitis or psoriasis) and $11 \%$ (57) had an urticarial or toxic erythematous disorder (for example, Henoch Schonlein purpura, erythema multiforme). The second commonest group of disorders $(26 \%)$ were those in whom a specific diagnosis was not made. The final miscellaneous group of $14 \%$ (75) included, for example, such diagnoses as sunburn reactions. benign naevi, pyogenic granuloma and bleeding strawberry naevi. Overall, only $10 \%(54)$ were spontaneously referred to a consultant clinic, the rest being managed in the A\&E department. Ten per cent of the 141 undiagnosed patients were referred.

\section{Prospective study}

During the 2-month study period, 83 patients with DD were referred from the A\&E department to an open-access clinic for validation of the diagnosis. Table 2 illustrates the age and sex distribution. Seventy-two per cent (60) occurred in pre-school children, almost three times the number in those aged 5-13 years. Sex distribution was equal in all age groups with the exception of infancy where males predominated in a ratio of 2:1.

The diagnoses made by junior doctors in the A\&E department and the consultant dermatologist have been compared (Table 1). Infections tended to be under-represented in junior doctors' diagnoses (26\%) compared with $41 \%$ of these by the consultant. Of the 15 patients in whom no diagnosis was made consultant to have an infection and six a papulos quamous disorder. Using these data a table of concordance (Table 3 ) has been constructed in which the principal diagonal represents diagnostic concordance in each dermatological group. Twenty patients were thought by the junior staff to have an infection and 34 by the consultant; hence the concordance rate was $20 / 34$ or $59 \%$. The concordance of diagnosis for papulosquamous disorders was $77 \%(24 / 31)$. In view of the small numbers in the other diagnostic groups the concordance rate is less valid. The overall rate of concordance between the junior doctor and consultant diagnoses was $66 \%(55 / 83)$ ( \pm 2 SEM).

Although 83 patients were referred to consultant clinics during the study period, a further 23 were considered to have either very minor DD or referral was overlooked; seven were thought to have napkin dermatitis, five urticaria, four each herpes stomatitis or a viral exanthem.

Table 2. Age and sex distribution of 83 referrals to the open-access dermatology clinic

\begin{tabular}{lrrr}
\hline Age (years) & Male & Female & Total \\
\hline$<1$ & 15 & 7 & 22 \\
$2-5$ & 19 & 19 & 38 \\
$6-9$ & 6 & 5 & 11 \\
$10-13$ & 6 & 6 & 12 \\
Total & 46 & 37 & 83 \\
\hline
\end{tabular}

\section{DISCUSSION}

Audit is increasingly regarded as an important component of medical practice. ${ }^{3}$ It has been stressed that audit should be educational and reflect actual 


\begin{tabular}{lcccccc}
\hline & \multicolumn{5}{c}{ Consultant diagnoses } \\
\cline { 2 - 6 } $\begin{array}{l}\text { Junior } \\
\text { doctors } \\
\text { diagnoses }\end{array}$ & Infections & Papulosquamous & Urticaria & Miscellaneous & $\begin{array}{c}\text { No } \\
\text { diagnosis }\end{array}$ & Total \\
\hline Infections & $20(59 \%)^{*}$ & 1 & 0 & 1 & 0 & 22 \\
Papulosquamous & 3 & $24(77 \%)^{*}$ & 0 & 1 & 0 & 28 \\
Urticaria & 2 & 0 & $6(55 \%)^{\star}$ & 0 & 0 & 8 \\
Miscellaneous & 2 & 0 & 3 & $5(71 \%)^{*}$ & 0 & 10 \\
No diagnosis & 7 & 6 & 2 & 0 & $0(0 \%)^{*}$ & 15 \\
Total & 34 & 31 & 11 & 7 & 0 & 83 \\
\hline
\end{tabular}

$\left[{ }^{\star}( \pm 2\right.$ SEM $\left.)\right]$

rather than abstract practice. ${ }^{4}$ The purpose of this audit was to evaluate diagnostic accuracy of DD by junior medical staff in an A\&E department.

The 7-month retrospective survey determined that patients with DD accounted for $4 \%$ of those attending the unit, most commonly in the 2- to 5-year-old age group. Ninety-three per cent of these attendances were parent referrals. This is much higher than in an earlier study of all new attendances carried out in this department where parent referrals accounted for $69 \%$ of a $4 \%$ random sample of 22617 patients; 5 more recently this figure was $77 \%$. $^{2}$ The very high proportion of parent referrals may also reflect the worry and embarrassment that often accompanies DD which drives parents to seek immediate help. In general, however, the parent referrals have a significantly higher proportion of inappropriate attenders, ${ }^{4}$ which places an unnecessary burden upon hospital services, when in many cases satisfactory management could have been provided by their GP. ${ }^{2,4,5}$

The retrospective survey also revealed that although in $26 \%$ the junior staff did not make a definite diagnosis, only $10 \%$ of these were referred for a specialist opinion. In addition, the overall referral rate for a second opinion was equally low $(10 \%)$. In the prospective study, individual diagnostic concordance for infections was only $59 \%$ ( \pm 2 SEM) (Table 3). It is important to find effective ways of improving the performance of junior staff by inservice education, and because infections accounted for $41 \%$ of all cases seen but were most often misdiagnosed or under-diagnosed (Table 3), easily accessible pictorial examples in A\&E of common infective conditions such as impetigo may be helpful.

Hunt and Glucksman have reviewed the complaints made about treatment received at an inner- one-third of patients missed diagnoses were an important aspect, which, at a time of increasing litigation, ${ }^{7}$ reinforces the desirability for diagnostic precision. As a result of this audit, particular attention to $D D$ is being given during induction courses for A\&E junior doctors together with the provision of an open-access consultant clinic to which immediate referrals should be made. The value of such a service is illustrated by two patients seen during the prospective study. One patient was thought to have cigarette burns, possibly as a result of child abuse. A dermatologist, however, considered bullous impetigo more likely and bacteriological cultures tended to confirm this. In a second patient, referral of a child with an 'eczematous rash' led to a diagnosis of Kawasaki disease. In such patients the implications for misdiagnosis can be serious and far reaching.

This audit has demonstrated several benefits of an open-access dermatology clinic. It encourages junior A\&E staff to seek prompt specialist advice for both diagnosis and management. In addition, the 'feedback' in the form of a letter, sent following the consultation to the referring A\&E doctor is an important specific educational component. Furthermore, many of the patients with papulosquamous disorders who attended the unit during the prospective study, were neither accidents or emergencies. Their concerns had either not been addressed or had been only partially relieved by their GP. These families clearly needed a specialist opinion in order to gain a more complete understanding of the disorder and its management, and an open-access dermatology clinic is a more appropriate setting to deal with these anxieties fully.

In practical terms, the referrals from A\&E to the open access clinics required no increase in outpatient staffing levels and as these patients were 
An audit

of dermatology seen at the end of each clinic or if time became available during the clinic, the waiting time for routine appointments was not affected. We feel therefore that this system with only minimal extra cost, has provided an enhanced service for patients, as well as additional postgraduate education for junior doctors in paediatric dermatology.

\section{ACKNOWLEDGMENTS}

The authors would like to thank Dr Lucia Dolan for help in collecting data, Dr Gilbert McKenzie for statistical advice, Mrs Marie Loughran for secretarial assistance and the nursing and medical staff of Dermatology Outpatients and Accident and Emergency Department of the Royal Belfast Hospital for Sick Children, for their cooperation.

\section{REFERENCES}

1. Korner E. (1982) (Chairman, Steering Group on Health
Services Information) First Report to the Secretary of State. HMSO, London.

2. Glasgow J.F.T. \& Glasgow A.J. (1992) Paediatric accident and emergency medicine: a challenge to paediatricians. In: Sibert J. (ed.) Accidents and Emergencies in Childhood. Royal College of Physicians, London (in press).

3. Department of Health (1989) Working for Patients. Cm555. HMSO, London.

4. Coles C. (1989) Self assessment and medical audit: an educational approach. British Medical Journal 299, 807-808.

5. Stewart M.C., Savage J.M., Scott M.J. \& McClure B.G. (1989) Primary medical care in a paediatric accident and emergency department. Ulster Medical Journal 58(I), 29-35.

6. Hunt M.T. \& Glucksman E. (1991) A review of seven years of complaints in an inner-city accident and emergency department. Archives of Emergency Medicine 8, 17-23.

7. Wyle W.D. (1988) Report of the President. The Medical Defence Union Annual Report, 7-8. 